\title{
The Digital Culture of Industry in the Transition to Sustainable Development
}

\author{
Irina Levitskaya ${ }^{1, *}$, and Martin Straka $^{2}$ \\ ${ }^{1}$ T. F. Gorbachev Kuzbass State Technical University, Mezhdurechensk branch, 652881, 36 \\ Stroiteley st., Mezhdurechensk, Kemerovo region-Kuzbass, Russia \\ ${ }^{2}$ Technical University Košice, Faculty BERG, Letná 9, 04001 Košice, Slovakia
}

\begin{abstract}
The digital transformation of economic and social sectors is conditioned by the need for a critical reflection of the cultural processes taking place in modern society under the influence of transition to sustainable development. The latter is accompanied with decreasing of waste and pollution, expanding of lean production, settling the new nonmaterial industries. Therefore, it is critically important to form special cultural conditions for industry digitalization - not for increasing use of natural resources, but for decreasing harmful influence on environment. The purpose of this article is an analytical review of the theory and methodology of the analysis of digital culture in the historical and sociocultural perspective. The analysis of modern theories of digital culture and approaches to the analysis of its formation, historical and cultural reconstruction of the formation of digital culture, the definition of the conceptual apparatus of digital culture research and information processes is carried out from a methodological position, according to which cultural research is based on the principles of historicism and functionality, priority of sustainable development values.
\end{abstract}

\section{Introduction}

Digital smart manufacturing is based on the constant, continuous interaction of elements of production industries and the social sphere. The logical form of functioning of the production process will be an organization on the principle of self-sufficient production modules, formed according to the characteristics of target orientation and the creation of consumer value. The new industrial ideology, based on the concept of global digital changes, is associated with the sequential iterative introduction of new technologies, techniques, materials that gradually change the methods and methods of production, the nature of labor, the relationship between producers and consumers, man and machine.

The ideological basis for the digital transformation of industries and the social sphere and the transition to sustainable development is a trend in the development of industry and technology in the 21 st century.

\footnotetext{
* Corresponding author: levitskaya ia@mail.ru
} 
The global digitalization trends that we can observe in industries, especially high-tech ones, reflect the nature and directions of digital transformation of manufacturing industries and the social sphere.

We live in the age of global digitalization, which is characterized by the transition to digital algorithms underlying this system. The modern world sets new tasks for education, which require the fastest possible response. The digitalization of social relations, on the one hand, helps to solve them, on the other, it creates new problems. The state, the executive branch, the legislature on the one hand, IT companies and telecommunications networks on the other, and thirdly, the teaching community will have to work together to improve technologies, modify teaching methods, and seek the optimal balance of digital and classical education. The emerging problems need to be analyzed at least at the legislative and executive levels, and possibly, at the maximum, in the technological and methodological context.

Digitalization is one of the ways to make education of the same quality for everyone. It is easier and faster to create a personalized approach to education, and it is easier to implement differentiated learning that takes into account the needs of everyone. The digital environment can create equal opportunities in inclusive education for people with special needs. Digital, among other things, is able to teach digital literacy and interaction with interfaces. These tasks are much easier to solve if digital technologies are integrated into the education process.

\section{Materials and Methods}

In the era of the ingression of digital technologies into basic industries, generating technological dynamism [1] and an accelerated transition to new types of energy [2], new investment instruments [3] and institutions [4], the role of a new culture - the digital one in ensuring the transition to sustainable development [5] is increasing.

Culture is one of the most complex interdisciplinary terms in modern language. This is partly due to the variety of complex connotations of the word in European languages, and partly for purely theoretical reasons, since the term "culture" is used in various disciplines. We will talk about digital culture as a system of mechanisms for social integration and the production of cultural goods based on the use of digital technologies, which determines the way of life and value-normative orientations of people.

We will refer to the phenomena of digital culture:

- personal computer and its modifications in the form of mobile devices [6];

- worldwide computer network Internet;

- artificial intelligence technologies;

- software and applications;

- immersion virtual reality environments (including 3D) [7];

- video games and multimedia systems;

- computer graphics and visualization (CGI) tools;

- digital formats of traditional means of communication (books, photographs, audio and video recordings, digital TV);

- modern technological art;

The phenomenon of digital culture is often associated with the global transformation of the media as the main means of communication and information provision - from broadcast and print, with the same content for all users, to personalized and network media based on digital technologies for the transmission and processing of information content. Digital technologies are changing the nature of information material (content): it becomes automated and based on digital databases. This leads to such global changes in digital information and the digital environment that we often understand digital culture as the 
culture of algorithmic processes (the so-called "algorithmic culture") - this is personalized content, social media channels, recommendation systems and personalized advertising on the Internet, etc. [8] At the same time, digital databases are much more flexible than nondigital ones and provide many opportunities - search engines, Internet platforms, social networks, etc.

Objects of digital culture, in contrast to traditional objects of cultural heritage (architecture, fine arts, other artifacts), are in constant change, and can be investigated in dynamics, as a process. This is due to the peculiarities of the digital network "hypertext" environment: collaboration, creativity, product sharing. Thus, objects of digital culture are not completely complete; access to information content of digital culture objects hyperlinks and social networks (for example, joint Internet creativity: fanfiction, Internet memes). Also, features of digital culture objects are the ability to change space and time as a result of their existence in virtual reality (for example, the creation of "synthesized" objects by combining objects or phenomena from different historical eras, changing the spatial and temporal context, etc.) [9].

The use of augmented and virtual reality in exhibitions, including museums and works of art, festivals and other cultural events, implies and ensures:

- getting instant access to information content,

- personalization of content (eg music, information at art exhibitions),

- visualization of "traditional" cultural objects and creation of an interactive environment.

Digital technologies make it possible to create virtual fictional worlds, to form a human experience-simulation in augmented or virtual reality. The objects of digital culture are computer and video games, which also simulate situations and create fictional autonomous worlds. Also, a person can create his "double" in a social network (avatar), giving him features and characteristics at will. Thus, a person in digital culture has a "second life", augmented reality, virtual space [10].

Digital culture is assessed by the possibility of access to the Internet, digital technologies, the level of computer equipment in workplaces and households, etc. However, is the fact of having access to digital technologies and devices a sign of a high level of development of digital culture? In fact, the fact of availability and access to technology is not an unconditional factor in the growth of efficiency, growth and development of both individuals and society. It is necessary to create a digital culture and digital literacy that allows a person to use and derive the maximum benefit from digital technologies.

Transformations in media are causing global changes in the way people communicate and interact in a social network, transferring them to the realm of virtual reality and digital technologies. As a result, there is a change in the patterns of human behavior and his perception of the surrounding reality, methods of communication and work with information. Thus, digital culture is not so much a technological phenomenon as a social one. Society today is more than ever immersed in a stream of technological innovations that shape our interactions and mediate our access to things and other people. Taking into account the above changes, features of digital culture, the question arises: how to carry out the study of digital culture? What phenomena, artifacts, processes, objects and objects should be studied?

The main blocks that should be explored if we want to understand the phenomenon of digital culture include the following:

- the nature of global changes that underlie social and technological transformations,

- the consequences of global changes and the introduction of digital technologies for the individual and society as a whole,

- study of theoretical information and empirical data in the field of digital culture and its consequences, 
- study of changes in social communications, activities (activities), including modern media and digital technologies / technology.

Still the question remains: how to understand what has the digital culture of a society, a country, and perhaps a person reached the level of development? What indicators would be more or less relevant if we came to the conclusion that the mere possession of a computer or a mobile phone cannot speak of a high level of digital culture. The level of development of digital culture can be assessed only through a set of indicators, the main of which include:

- human involvement in digital processes, the digital environment,

- the nature of the use of digital technologies,

- how the use of technology contributes to the development and growth of a person, society, enterprise, state,

- creativity and innovativeness (development of high-tech industries, jobs, creation of innovations, etc.),

- increase in labor productivity - the introduction of high-performance equipment and technologies in production and work processes,

- availability of technologies.

If we consider the process in the totality and complexity of all elements, then the following components need to be digitalized:

- creative culture,

- entrepreneurial culture,

- digital Marketing Skills,

- new media, virtual and augmented reality as an integral part of everyday life and work.

As innovative technologies become more prevalent, the demand for skills, competence and innovation in the application of these technologies will continue to grow. Exploring digital culture, the question inevitably arises: is the border between virtual reality and material reality impenetrable? Is virtual reality really the result of digitalization and the spread of digital technologies? The perception of the world by man has always had a dualism, and there was both virtual reality (the world of ideas, fictional characters, cultural values and works of art, etc.) and real, that is, material (physical) reality. The whole culture, in principle, is in virtual reality - all cultural objects, values are important not as utilitarian physical objects, but at the level of emotional perception, and only for a person. Therefore, digital culture is a phenomenon of culture in terms of its spatial location, but in immersion in digital technologies and environment.

\section{Results and Discussion}

The phenomenon of digital culture has led to the formation of new sciences that study objects and objects that were unknown or did not exist before the widespread dissemination of digital technologies. These sciences include: digital ethnography, digital semiotics, digital hermeneutics.

Digital ethnography studies various types of data and digital communication media (social networking sites, blogs, forums, gaming environments, websites, dating sites, Wikipedia, etc.). The subject of research in digital ethnography is the communicative practices of people in online communications; ways of creating semiotic materials circulating in the global environment; new digital communities (Digital Tribe) [9].

The main subject areas of digital semiotics include: computer visualization of texts, problems of interpretation of visual texts generated by visualization systems, computer modeling, design and use of visual systems.

Digital hermeneutics is the analysis and interpretation of text in contextual immersion in the cultural environment, the study of cybertexts. It is becoming especially relevant in the 
context of digital media and digital content on the Internet. Digital hermeneutics explores the problems of authenticity, truthfulness, reality of information and data obtained from various sources.

Thus, the emerging "digital culture", on the one hand, requires critical reflection within the framework of cultural analysis - testing technologies for their cultural consistency and value in the aspect of analyzing the fundamental problems of transforming culture and society: the catastrophic nature of social processes, dehumanization, etc. On the other hand, it is required to update the very culturological knowledge and the ways of its transmission in society, taking into account the possibilities and requirements of new technological realities. Therefore, the combination of critical analysis with constructive solutions of an educational nature would make it possible to more effectively integrate culturological knowledge into the context of modern digital culture.

Cultural studies of informatization processes face the methodological necessity of defining a specific subject of research and entering into an interdisciplinary dialogue with other disciplines and approaches. To solve this problem, modern researchers introduce new search terms and concepts: "cyber culture", "digital culture", "virtual culture", "network culture". Obviously, informatization should be attributed to those technological capabilities that make it possible in the logic of development, evolution, modernization, etc. It is also important to keep in mind that informatization is the result of the reproduction of certain cultural attitudes, such as the values of rationality, efficiency, versatility. The key issue of studying the problems of culture and technological development, the formation of digital culture lies in the plane of the contradictions of cultural and technological determinism and the search for their complex configurations.

Today we live in an era based on the 4th revolutionary wave of innovations and inventions - the Internet, additive manufacturing, artificial intelligence, neural networks, unmanned aerial vehicles, robotic systems, including cyber-physical systems, 3D printing, etc.

PriceWaterHouseCoopers research "Industry 4.0. Creation of a digital enterprise" the transition to a digital production model and the creation of digital educational content implies the following main directions of changes: digitalization of educational processes, digitalization of educational products, implementation of digital business models and providing access to subjects of the educational process. Changes are expected in several directions.

Digitalization and integration of business processes vertically (within the product life cycle, from development to production, including the purchase of the necessary resources, service, logistics) and horizontally, which implies the unification of suppliers, consumers and all key partners in the value chain into a single system products.

The introduction of digital technologies will increase the efficiency of operational management, planning, quality management, etc. due to constant monitoring in real time in a single integrated network, the use of augmented reality technologies and data management.

Digitalization of manufactured products and services, namely the digital addition of "traditional" products, as well as the production of innovative digital products. Digitalization will allow industrial enterprises to have access to information and data on the use and operation of manufactured products by the end user and to modernize and improve the product in accordance with the requirements and requests of consumers.

Implementation of digital business models and provision of access to subjects of the educational process. The digitalization of business models involves the involvement of the end consumer in business processes, which will allow to optimize the process of interaction with consumers, including through a comprehensive individualized (customized) approach based on common digital platforms and data. The digitalization of production and the 
introduction of the technology of the future into the production process is implemented in strict accordance with the system-wide laws of development.

Digitalization began to have a significant impact on culture due to the emergence of the Internet as a mass form of communication and the widespread use of personal computers and other digital devices, such as, for example, smartphones, which led to the formation of the phenomenon of digital culture. Digital technologies have penetrated into human life so much that the study of digital culture potentially covers all aspects of everyday life and is not limited to the Internet or modern communication technologies.

The concept of digital culture is viewed as an ideology of management and functioning of socio-economic systems based on the penetration and sharing of digital technologies. This phenomenon of human society is based on global changes in interaction, communications and technologies of human life, in intrasystem processes and in the interaction of the system with the external environment.

The concept of digital culture includes norms, rules, traditions, methods and forms of communication and decision-making. The central core of digital culture is a system of values that characterize how an organization (system) promotes and supports the use of digital technologies in the process of its functioning with the aim of the greatest efficiency.

Thus, the term "digital culture" denotes a single information technology space for presenting a clear and almost complete transformation of the world with the help of digital technologies, which will ensure the unification of individual components of the system and elements of the external environment into a single production super-system.

Digital culture reflects the stage of development of the cultural phenomenon of society in the 21 st century, based on digital communication technologies and digital social networks, digital images and visualization, virtualization of space and the material world, the formation of a value system based on digital and information technologies and systems.

The phenomenon of digital culture is often associated with the global transformation of the media as the main means of communication and information provision - from broadcast and print, with the same content for all users, to personalized and network media based on digital technologies for the transmission and processing of information content.

Digital technologies are changing the nature of information material (educational content in this case): it becomes automated and based on digital databases. This leads to such global changes in digital information and the digital environment that we often understand digital culture as the culture of algorithmic processes (the so-called "algorithmic culture") - this is personalized content, social media channels, recommendation systems and personalized advertising on the Internet, etc. At the same time, digital databases are much more flexible than non-digital ones and provide many opportunities - search engines, Internet platforms, social networks, etc.

\section{Conclusion}

As a result, there is a change in the patterns of human behavior and his perception of the surrounding reality, methods of communication and work with information. Thus, digitalization is not so much a technical and technological phenomenon as a social one.

Today, digitalization at the level of business, government and society allows countries to expand their areas of presence and compete with each other in the global market, thereby increasing the quality and standard of living of the population within the country. Currently, a successful practice of digital transformation has appeared in many areas - digitalization has ceased to be an abstract concept and has become a reality, and the Russian IT industry today is one of the active players in the global digital transformation market.

Transformations in the IT-industry are causing global changes in the way people communicate and interact in a social network, transferring them to the realm of virtual 
reality and digital technologies. The movement observed in society towards computerization, informatization and the creation of a developed information and educational environment presupposes the use of such an important component as digital educational content. Digitalization and the transition sustainable development on a global scale contributed to the formation of a fundamentally new technology for obtaining education - Massive Open Online Courses. MOOC appeared in the early 2000s for free access on the world wide web. The demand for such educational services turned out to be in demand, and now many world universities have new educational content at their educational sites - teaching materials, lecture courses on various topics and the most popular specialties.

The movement observed in society towards infocommunication and digitalization of social relations is ensured by the creation of a developed information and educational environment. The introduction of digital technologies increases the efficiency of management through continuous operational management, planning, quality management, etc. in a single integrated network, using augmented reality technologies and data management. The digital transformation of economic and social sectors enables industrial enterprises to have access to information and data on the use and operation of manufactured products by the end consumer and to modernize and improve the product in accordance with the requirements and requests of consumers. Digitalization of manufactured products and services, namely the digital addition of "traditional" products, as well as the production of innovative digital products, is the essence of innovation in terms of digitalization.

\section{References}

1. E.A. Gasanov, A.E. Zubarev, Economics and Innovation Management, 2, 23-29 (2020) DOI: $10.26730 / 2587-5574-2020-2-23-29$

2. M. Beer, R. Rybár, M. Cehlár, S. Zhironkin, P. Sivák, Energies, 13(10), 2450 (2020)

3. M.E. Konovalova, O.Y. Kuzmina, S.A. Zhironkin, Lecture Notes in Networks and Systems, 84, 180-188 (2020)

4. M.A. Klimovich, Economics and Innovation Management, 1, 18-25 (2019) DOI: 10.26730/2587-5574-2019-1-18-25

5. K.B. Kvitko, Economics and Innovation Management, 1, 26-35 (2019) DOI: 10.26730/2587-5574-2019-1-26-35

6. J. Morato, A.Ruiz-Robles, S. Sanchez-Cuadrado, Technologies for Digital Inclusion: Good Practices Dealing with Diversity (Carlos III University, Madrid, 2016)

7. R.E. Botelho-Francisco, A Netnographic Approach on Digital Emerging Literacies in the Digital Inclusion Program AcessaSP (Carlos III University, Madrid, 2016)

8. W. Teixeira, R. Vergili, Digital Inclusion and Computational Thinking: New Challenges and Opportunities for Media Professionals (University of Sao Paulo, Sao Paulo, 2018).

9. B.M. Neto, Handbook of Research on Comparative Approaches to the Digital Age Revolution in Europe and the Americas (University of Brasilia, Rio de Janeiro, 2016)

10. A. Cuevas-Cerveró, Digital Inclusion: From Connectivity to the Development of Information Culture (Complutense University of Madrid, Madrid, 2016) 